\title{
ОСОБЕННОСТИ РАЗВИТИЯ И СТАНОВЛЕНИЯ КЛАССИЧЕСКОЙ ТЕОРИИ ЭЛИТ
}

\begin{abstract}
Аннотация: Предметом данного исследования является рассмотрение вопросов связанных с развитием и становлением классической теории элит, а так же подходов связанных с классической теорией элит:репутационного, плюралистического, ценностного, элитического, путем анализа работ таких известных мыслителей как : В. Парето, Г. Моска, Р. Михельс, М. Вебер, Р. Миллз, Н.А. Бердяев. особое внимание уделяется изучению так называемого «элитного круга» то есть лии входящих в элиту, проводится разграничительная черта между элитой и лицами не являющимися таковой. Так же автором определяются общие характерные черты присущие учениям об элитах разных авторов. в процессе исследования автором были использованы метод сравнительно правой, метод анализа и синтеза, данные методы применялись т.к. именно с их помощью можно более точно отразить проблему исследования. Результатом исследования является более подробное изучение вопроса становления и развития классической теории элит. Основными выводами данного исследования является выведение общих признаков присущих элите, так же автор дает свое собственное определение термину "элита». В дальнейшим используя результат данного исследования можно более глубоко рассматривать теорию элит.
\end{abstract}

Ключевые слова: Теория элит, классическая концепция элит, проблема элит, элита, рекрутирование элит, понятие «элита», признаки элиты, состав элиты, общее черты элиты, особенность элиты.

Abstract: The subject of this research is the review of the issues pertaining to development and establishment of the classical elite theory, as well as the approaches associated with it: reputational, pluralistic, value, and elite, by analyzing works of such renowned thinkers as Vilfredo Pareto, Robert Michels, Max Weber, Nikolai Berdyaev, and others. A special attention is given to the study of so-called "elite circle", or individuals who are part of the elite. The author identifies the general characteristic features inherent in the teachings about the elites in the writings of various scholars. The main conclusion of this research is the determination of the general signs intrinsic to the elites; the author also gives an original definition to the term of "elite". The results of this work can be used to further examine the elite theory.

Keywords: General features of the elite, members of the elite, signs of elite, definition of elite, recruitment of elites, elite, problems of elites, classical elite concept, elite theory, elite features.

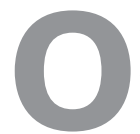

собенностью жизни любого общества на современном этапе является объективное осознание существующих политических реалий, более объективная оценка политической элиты. Мировой опыт показывает, что главной движущей силой в модернизации страны выступают ее элиты, основным инструментов в руках элиты является государство. Термин «элита» происходит от французского «elite» (лучший, отборный, избранный). C XVII в. он употребляется для обозначения товаров высшего качества, а затем и для выделения в обществе высшей знати. В Англии этот термин стал применяться к высшим социальным группам. Однако термин «элита» не применялся широко в общественных науках до конца XIX - начала XX вв. (то есть до появления работ В.Парето), а в США - до 30-х гг. нашего столетия.

Основы концепций элит заложены в трудах итальянских социологов Гаэтано Моска, Вильфремо Парето и немецкого политолога Роберта Михельса.

Моска Г. в своем труде «Основы политической науки» (1896 г.) предпринял попытку доказать деление общества на класс управляющих и класс управляемых сформулировав закон социально-политической дихотомии общества. Первый осуществляет все политиче- 
DOI: $10.7256 / 1811-9018.2015 .8 .15010$

При цитировании этой статьи сноска на доі обязательна

\section{Право и политика 8 (188) 2015}

ские функции, монополизирует власть и пользуется преимуществами; второй управляется и регулируется первым и поставляет материальные средства для жизнеобеспечения политического организма. Г. Моска считал господство меньшинства неизбежным, потому что это господство организованного меньшинства над неорганизованным большинством. В своих трудах Г.Моска выделил элиту как объект социального исследования, провел анализ ее, рассмотрел законы формирования элиты, структуру, причины упадка и смены контр-элитой. [2]. Понятие «Элита» Моска отождествлял с понятиями : «правящий класс» и «политический класс» употребляя их как синонимы. В последствии Г. Моска внес коррективы в данные понятия и стал рассматривать политический класс в качестве базиса для правящего класса. При этом Моска утверждал , что политология прежде всего является наукой об элитах. Главной опасностью для элит Моска называл стремление элиты превратиться в наследственную закрытую группу объясняя это тем, что такое превращение приведет элиту к вырождению и замене контр-элитой. Моска отмечал, что идеальна та элита, которая с одной стороны закрыта , а с другой стороны обеспечивает определенную преемственность, причем преемственность является главной гарантией устойчивости любой элиты, особенно политической. Элита должна формироваться не на основе богатства и родовитости, а на основе способностей, образования и заслуг. В последствии данные идеи Моска выдвигал в теории меритократии. Однако Моска выдвинул тезис, что между властью и богатством существует двусторонняя связь, с одной стороны богатство создает власть, а с другой власть создает богатство. В данном тезисе проявляется внешнее сходство с марксистской концепцией общественного устройства, но на этом все сходство и заканчивается , так как в концепции Моски в отличии от концепции Маркса фундаментом общественного развития служит не экономика, политика, не базисные отношения, а надстроичные - политические. Объясняя это тем, что правящий (политический) класс концентрирует руководство политической жизнью в своих руках, объедения индивидов обладающих политическим сознанием и решающим влиянием на экономику и экономическую элиту. [2] В результате Моска ставит под сомнение сам термин «Демократия», обозначая демократию камуфляжем для власти меньшинства. Что вполне закономерно ведь именно власть меньшинства легитимизируется через большинство. Одной из причин упадка элиты Моска связывал утрату тех качеств с помощью которых эта элита пришла к власти, либо отсутствие адекватной политики в новой социальной среде.
Еще одним значимым ученым внесшим вклад в формирование теории элит был В. Парето. Парето так же из ходил из принципа, что миром во все времена правило и должно править меньшинство, именуемое «элита». В своей теории элит В.Парето отмечал, что люди изначально не равны в своем физическом, нравственном и интеллектуальном отношении. В результате чего неравенство в обществе Парето рассматривает как вполне естественное, реальное и очевидное явление.[1] Люди обладающие наиболее высокими показателями в той или иной области и составляют элиту, как следствие в каждой сфере деятельности существует своя элита. Парето выделяет два вида элиты: правящую (т.е. принимающую участие в осуществлении политической власти) и не правящую. Правящая элита немногочисленна и представляет собой «высший слой», а остальная часть составляет «низший слой». Парето отмечает, что элиты существуют во всех обществах независимо от формы правления. Трактовка понятия «элита» у Парето носит более описательный характер без внесения в него оценочного элемента. Однако Парето не смог избежать противоречия при трактовке понятия «элита». С одной стороны, он характеризует представителей элиты как наиболее способных и квалифицированных в определенном виде деятельности, как своего рода результат естественного отбора. С другой стороны, в «Трактате» встречаются утверждения, что люди могут носить «ярлык» элиты, не обладая соответствующими качествами. Парето отмечал, что между элитой и остальной массой населения постоянно происходит обмен, часть элиты переходит в основную массу населения, а наиболее способные из основной массы пополняют элиту. Данный процесс Парето называет циркуляцией элит. Так же Парето утверждает, что циркуляции элит имеет фундаментальное значение для поддержания социального равновесия. В случае отсутствия циркуляции элит или слишком медленной циркуляции происходит деградация элиты, что, в конечном счете, приводит к ее упадку. При этом Парето справедливо отмечает, что в низшем слое растет число индивидов имеющих необходимые для управления качества, тем самым создается благоприятная почва для захвата власти либо государственного переворота. При этом Парето объясняет процесс циркуляции элит тем , что каждый тип элит обладает определенными преимуществами, но с течением времени те или иные преимущества перестают соответствовать либо отвечать существующей социальной и политической ситуации. В результате Парето приходит к выводу, что новая энергичная элита неизбежно вытеснит ранее существовавшую, 
эволюционным либо революционным путем. Парето отмечать , что любая элита неизбежно деградирует. В своей теории элит Парето выделил определенные типы людей внутри элиты:

- люди-лисы, такой тип людей который прибегает к хитрости и избегает конфликтов;

- люди-львы, такой тип людей, которые придерживаются привычного и не боятся конфликтов и силы.[4]

В стабильной элите Парето справедливо отмечает на преобладание «львов», напротив неустойчивая элита преобладает «лисами» но при этом такая элита динамично развивается. Так же Парето указывает на существование элиты «спекулянтов» в данной элите происходит инициатива к изменениям и социальноэкономическому прогрессу. И последним вид элиты Парето именует «рантье» данный вид элиты он отождествляет со стабильностью, противодействием опасности, которая исходит от элиты спекулянтов. Таким образом, Парето приходит к выводу, что среди элит должен присутствовать баланс. Дисбаланс же приводит к кризису. Для устойчивого развития общества элиты должны находиться в постоянной борьбе. А сохранение социального равновесия требует смены элит. Как следствие Парето выдвинул тезис «историякладбище элит».

Несмотря на сходство основных идей Парето и Моски в их концепциях есть различия:

- $\quad$ Парето делал упор на замене одного типа элиты другим, а Моска на постепенном проникновении в элиту «лучших» представителей масс;

- Моска возводит в абсолют действие политического фактора, а Парето объясняет динамику элит применяя психологические факторы; элита властвует потому, что насаждает политическую мифологию, возвышаясь над обыденным сознанием.

- Для Моски элита - политический класс. У Парето понимание элиты шире, оно антропологично.

Наряду с Парето и Моской, проблемой элит занимался Р.Михельс. В отличии от Парето и Моски , Михельс изучал в первую очередь политические партии а не все общество в целом. Михельс сделал вывод, раз общество является сложной организационной структурой , то оно должно быть разделено на классы (элиты). Сложная социальная структура общества порождает сложную управленческую структуру в результате в таких условиях формируется узкая управленческая группа. Михельс признавал важность необходимости классовой борьбы , тем самым соглашаясь с Марксом. Михельс отмечал, что представительная демократия несет в себе зародыш олигархии. В последствии
Михельс сформировал «железный закон олигархических тенденций» связывая этот закон прежде всего с выделением элиты - активного меньшинства, которому масса должна довериться, так как не может осуществлять свой прямой контроль над этим меньшинством. Поэтому демократия неизбежно превращается в олигархию.[6] Суть «железного закона олигархических тенденций» состоит в том, что неотделимое от общественного прогресса развитие крупных организаций неизбежно ведет к олигархизации управления обществом и формированию элиты, поскольку руководство такими объединениями не может осуществляться всеми их членами. Эффективность их деятельности требует функциональной специализации и рациональности, выделения руководящего ядра и аппарата, которые постепенно, но неизбежно выходят из-под контроля рядовых членов, отрываются от них и подчиняют политику собственным интересам, заботятся в первую очередь о сохранении своего привилегированного положения. Рядовые же члены организаций недостаточно компетентны, пассивны и проявляют равнодушию к повседневной политической деятельности. В результате любой, даже демократической организацией всегда фактически правит олигархическая, элитарная группа. Такие наиболее влиятельные группы, заинтересованные в сохранении своего привилегированного положения, устанавливают между собой различного рода контакты, сплачиваются, забывая об интересах масс.

Помимо классической теории элит существует ряд подходов к ее изучению. Неразрывно связанными с классической теорией элит являются два подхода: элитический и плюралистический, при этом концепция элитистов выступает своего рода продолжением в развитии классической теории элит. Так к примеру Райт Миллз являясь одним из авторов элитической модели общества указывает на то, что основные направления государственной политики определяет политическая (властная ) элита. При этом в состав властной элиты входят: 1) руководители крупных организаций, корпораций ; 2) лица занимающие определенные военные чины , всегда высокие ; 3) определенная группа политиков. Представители властной элиты вынуждены действовать скоординировано, сообща, чтобы сохранить свое положение. Из позиции Р. Миллза можно сделать вывод, что представители разных элит (политической, военной, бизнес элиты) объединяясь в властную элиту подвергаются в определенной степени процессу интеграции , что неизбежно влечет за собой как вмешательство представителей одной элиты в дела представителей другой элиты, так и создание определенной системы 
DOI: $10.7256 / 1811-9018.2015 .8 .15010$

При цитировании этой статьи сноска на доі обязательна

\section{Право и политика 8 (188) $\bullet 2015$}

сдержек и противовесов. как следствие при взаимодействии различных элит и объединении их в более крупную элиту, при сохранение квалифицирующих признаков (бизнес элита, военная элита, культурная элита, и.т.д.) традиционной элиты происходит уменьшение автономии элит. Но при этом власть остается в руках отдельной «верхушки общества» из которой ряд членами не входит в правительство, но обладает более существенными ресурсами.

Существует и другая элитистская модель, автором которой является М. Вебер. Исходя из его теории внимание надо концентрировать на бюрократах, т.е. на должностных лицах, назначаемых на любом уровне, лица которые являются неотъемлемой частью работы государственных учреждений. М. Вебер представляет элиту как «армию чиновников» так как все учреждения обладающие государственно-властными полномочиями и не только подконтрольны бюрократической системе. И именно посредством «мелких» чиновников ежедневно приходящих на работу и исполняющих свои функции осуществляется реализация определенных задач и достижение поставленных целей. А самым главной заслугой «мелких» чиновников является управление общественными процессами.

Современные представители элитистской теории отрицают дихотомическое деление общества на небольшую правящую группу и всех остальных людей. Так например Р.Д. Патнэм разделил общество на шесть частей (страт) руководствуясь принципом обладания властью (под властью в данном случае понимается степень влияния на принятие политических решений). [8] И так первая группа лиц представляет собой тех кто непосредственно вовлечен в политику, тех кто ее осуществляет, например президент, правительство, законодательные органы и т.п. Вторая группа это те к кому представители первой группы обращаются за советом при принятии каких либо решений их мнение учитываются, а их санкций опасаются. К представителям данной группы можно отнести крупных бизнесменов , олигархов, лидеров общественных объединений, лиц занимающих высокие военные посты, другими словами данную группу можно именовать лоббистами. Третья группа представлена теми кто незначительно влияет на принятие политических решений, члены партий бюрократы среднего звена, руководители местных СМИ. Четвертая группа представлена теми для кого политика своего рода зрелище , они обсуждают ее но ни какого влияния на политику не оказывают. Пятая группа это «серая масса» граждан которые влияют на принятие политических решений только посредствам волеизъявления на голосовании. И шестая группа представлена лицами которые являются объектами а не действующими фигурами политики.[9]

Наряду с элитистским подходом существует и плюралистический подход, представителями которого являются Роберт Даль и Йозеф Шумпетер. В своей теории данные ученые указывают, что деньги, престиж, доступ к СМИ являются ресурсами политической власти. Принимая во внимание, что ресурсы политической власти широко распространены , они не могут быть монополизированы. При этом существует огромный ряд учреждений которые обладают власть в той или иной сфере ( культура, оборона, наука и образование и т д). А так же власть располагается на различных уровнях региональная , муниципальная. В результате чего, определить круг лиц к которому принадлежит власть практически невозможно.[7] В плюралистической теории власть и руководство общественными делами широко распространено и разделено между значительным числом организаций (как правительственных так и неправительственных). Важным элементом является автономность таких организаций друг от друга, а в какой-то степени и от правительства. В связи с этим политика представляет из себя бесчисленное множество компромиссов и договоренностей при принятий решений. При этом не следует отождествлять, что какая либо организация является отдельной элитой, наоборот отдельный вид элиты представлен совокупностью таких организаций. Борьба за власть происходит в жесткой конкуренции при этом каждая сторона пытается удовлетворить потребности своих приверженцев, что является вполне логичным и обоснованным. Таким образом, по мнению плюралистов конкуренция обеспечивает удовлетворение интересов всех граждан вовлеченных в политику. Справедливо отмечается, что такая борьба осуществляется в большинстве случаев на региональном уровне. По вопросу принятия решений национального масштаба плюралисты соглашаются с элитистами в плане того, что принятие такого рода решений остается за представителями небольшой группы лиц сосредоточивший в своих руках достаточное количество ресурсов политической власти.

Интересным представляется репутационный подход к пониманию элиты представленный Р.Ж. Щварцбергом в своей работе «Абстрактное право» он характеризует элиту как определенную касту которая представляет собой «треугольник власти» состоящий из политиков, деловых кругов и высшей администрации. Власть данной касты абсолютна и является следствием если государство не придерживалось принципа разделения властей. 
Необходимо уделить внимание ценностному подходу к определению значения элиты, представителями которого являются Х.О. Гасссет и Н. Бердяев, в своих трудах данные авторы рассматривали элиту как творческую и наиболее продуктивную часть общества. Представителе ценностного подхода к изучению элиты указывали на то, что элита обладает интеллектуальным превосходством над другими индивидами, а так же более высоким нравственным уровнем развития. Противопоставляя духовную элиту , творящую блага, ценности «серой массе» которая пассивна Х.О. Гасссет указывал, что принадлежность к «серой массе» носит чисто психологический характер, выраженный консервативным настроением ее представителей, т.е. не желанием что либо менять в своем укладе и использованием традиционных средств и методов. Таким образом под элитой X.О. Гасссет понимал совокупность лиц которая стремится к преобразованию и созданию общественных благ, а принадлежность к элите носит чисто психологический характер.

Согласно Бердяеву в общественном развитии действует так называемый нравственный закон дух которого выражается через качественный подбор личностей . Такие Личности образуют аристократию обладают такими признаками как высокая нравственность, духовное благородство, щедрость, жертвенность, осознание своего превосходства. В результате чего элита определена как привилегированная группа лиц обладающая высокой нравственностью, духовностью, щедростью и осознающая свое превосходство.

Таким образом в заключении необходимо отметить, что Г. Моска, В. Парето, Р. Михельс сформулировали классическую теория элит. А представители различных подходов (репутационный ,ценностный, плюралистический, элитический и институционный) продолжили ее развитие, несмотря на расхождение во взглядах на представление элит можно выделить ряд квалифицирующих признаков (принципов) которые характерны для представителей той или иной элиты:

1. Политическая власть, как и другие социальные блага, распределены неравномерно.

2. Люди делятся, как правило на тех кто имеет власть или наделен какими либо контрольно властными функциями и на тех кто не имеет власти.

3. Элита однородна и единообразна. Вне зависимости от вида элит ее представители хорошо знакомы между собой, имеют общие цели и интересы, а так же схожие взгляды на проблемы затрагивающие деятельность той элиты членами которой они являются.

4. Элита это самодостаточный и отдельный сегмент общества. Как правило при благоприятных условиях рекрутирование в элиту осуществляется из близких и привилегированных масс.

5. Элита автономна. Члены той или иной элиты решают касающиеся их вопросы самостоятельно и подотчетны только перед своей элитой.

6. Элита представляет собой движущую силу развития общества, либо революционным путем, либо эволюционным путем, такое развитие происходит в результате борьбы элит.

Исходя из вышеназванного можно сформулировать обобщающее понятие элиты. И так под элитой понимается совокупность лиц являющихся меньшинством в своей сфере деятельности объединенные общим интересами и целями ,которым удалость сосредоточить определенные контрольно-властные полномочия в своих руках, способные самостоятельно принимать решения касающиеся их функционирования, определения направления развития, решения наиболее важных проблем.

\section{Библиография:}

1. Вильфредо Парето: История - кладбище элит. // Политическая мысль. П.Рахшмир. - Пермский госуниверситет, 2000.

2. Г. Моска «Основы политической науки». Перевод с испанского / Санистебан Л.С.; Пер.: Заболотный В.Л. - М.: МП Владан, 1992.

3. Василенко И.А. Политология: учебник-3-е изд., перераб. И доп. - М.: Юрайт,2011.

4. Политология: Учебное пособие / Под ред. А.С. Тургаева, А.Е. Хренова. - СПб.: Питер, 2005.

5. Общая и прикладная политология: Учебное пособие. / Под общей редакцией В.И. Жукова, Б.И. Краснова. - М.: МГСУ; Изд-во “Союз”, 2007.

6. Политология: учебник, под ред. В.Н. Лавриненко-4-е изд., перераб и доп. - М.: Юрайт , 2012

7. Даль Р. Введение в экономическую демократию. М., 1992. Макарин А.В. Бюрократия в системе политической власти. С.Пб., 2000

8. Демократия в движении: эволюция социального капитала в современном обществе «(под редакцией Роберта Д. Патнэма), Oxford University Press, (2002)

9. Р.Д. Пантэм, Сравнительное исследование политических элит 1976 г. 
DOI: $10.7256 / 1811-9018.2015 .8 .15010$

При цитировании этой статьи сноска на доі обязательна

\section{Право и политика $8(188) \cdot 2015$}

\section{References (transliterated):}

1. Vil'fredo Pareto: Istoriya - kladbishche elit. // Politicheskaya mysl'. P.Rakhshmir. - Permskii gosuniversitet., 2000.

2. G. Moska «Osnovy politicheskoi nauki». Perevod s ispanskogo / Sanisteban L.S.; Per.: Zabolotnyi V.L. - M.: MP Vladan, 1992.

3. Vasilenko I.A. Politologiya: uchebnik-3-e izd., pererab. I dop. - M.: Yurait,2011.

4. Dal' R. Vvedenie v ekonomicheskuyu demokratiyu. M., 1992. Makarin A.V. Byurokratiya v sisteme politicheskoi vlasti. S.Pb., 2000

5. R.D. Pantem, Sravnitel'noe issledovanie politicheskikh elit $1976 \mathrm{~g}$. 